\title{
Michael Hamacher, Martin Eisenacher, and Christian Stephan (eds). Data Mining in Proteomics: From Standards to Applications. Methods in Molecular Biology Series, Springer, Heidelberg, Germany; 2011, 432 pp, ISBN 978-1-60761-986-4; (hard cover)
}

\section{Luisa Rusconi}

Published online: 7 February 2012

(C) Springer Science+Business Media, LLC 2012

The field of data mining in proteomics is currently extremely dynamic while encompassing a wide range of specialties, topics, and implications, and so is this book. It reflects in fact the diverse critical requirements and directions of the ongoing, very much needed effort to bring proteomic data handling, interpretation and exchange to the same advance level as the methods and technologies to get those data, which have often developed much faster.

The first book section dedicated to instruments and methods for data generation focuses exclusively on twodimensional electrophoresis and mass spectrometry (MS), a somewhat limiting selection to me in that it might have been worth including further approaches, such as protein arrays or techniques for protein-protein interaction studies. It is also not clear why MS imaging methods are not included, even if the relevant data format is later illustrated. The two subsequent sections dealing with databases (DB) and standards provide a very effective and comprehensive picture of both the historical evolution of these subjects and the key international standardization projects still underway, together with practical work implications. A section is then dedicated to the processing and interpretation of data putting clear didactic chapters besides chapters describing new data and ideas, such as the identification of alternatively spliced transcripts by proteomics informatics, or the virtuous circle to be fed between mass spectral DB matching and new hypotheses on mass spectral patterns. After an easily readable and helpful section describing several practical tools, the last section tackles modeling and systems biology. This is a very interesting compendium of theoretical, almost philosophical contributions next to requirements and tools with suggestions for their integration.

Overall the book is a valuable aid for beginners and for experts as well; moreover, it provides some stimulating materials for discussion in an open perspective.
L. Rusconi $(\bowtie)$

Oncology, Biotechnology Department, Nerviano Medical

Sciences, 20014 Nerviano, Italy

e-mail: luisa.rusconi@nervianoms.com 